\title{
An Option to Avoid the Sudden Mass Influx of Migrants Resulting From Worldwide Environmental Threats
}

\author{
Hirotaka Fujibayashi $^{1} \&$ Mikiyasu Nakayama ${ }^{1}$ \\ ${ }^{1}$ Graduate School of Frontier Sciences, The University of Tokyo, Kashiwa, Japan \\ Correspondence: Hirotaka Fujibayashi, Graduate School of Frontier Sciences, The University of Tokyo, 5-1-5 \\ Kashiwano-ha, Kashiwa, Chiba 277-8563, Japan.
}

Received: April 5, 2017

doi:10.11114/ijsss.v5i6.2397
Accepted: April 24, $2017 \quad$ Available online: May 4, 2017

URL: https://doi.org/10.11114/ijsss.v5i6.2397

\begin{abstract}
This study attempts to explore useful and practical measures to mitigate the anticipated impacts on host communities caused by the mass influx of migrants resulting from worldwide environmental threats. Concern for worldwide environmental threats such as climate change, deforestation, and sea -level are on the rise, meaning that many people from all over the world may become environmentally displaced persons (EDPs). Unless we take some corrective measures, the world could face grave difficulties resulting from massive displacement of EDPs in the near future. Human migrations generally occur for a variety of reasons and under different circumstances, and they potentially have strong effects on host communities. When massive numbers of migrants flow into one country all at once, worries about severe conflicts between migrants and residents in the host community emerge. Against those concerns, we propose an option that avoids the sudden mass influx of migrants resulting from environmental threats and; resettling them instead as economic migrants in a manageable fashion. This option seems preferable both for migrants and for the host community, rather than tackling a mass migration that would occur after the slow-onset effect of environmental threats.
\end{abstract}

Keywords: EDPs, displaced, migration, resettlement, mass -influx, host community, conflicts

\section{Introduction}

\subsection{Disputes Surrounding Environmentally Displaced Persons}

Attention to environmental disruption or climate change grows, the issue related to those who are displaced by environmental disruption or climate change, so-called environmentally displaced persons (EDPs), has also become a global concern. The concept of EDPs appeared in the mid-1980s to the early 1990s. El-Hinnawi (1985) defined "environmental refugees" as "those people who have been forced to leave their traditional habitat, temporarily or permanently, because of a marked environmental disruption (natural and/or triggered by people) that jeopardized their existence and/or seriously affected the quality of their life.” (p. 4). Academics and campaigners have also proposed a variety of terms or definitions regarding this issue.

There are various disputes around whether or not EDPs really exist and what term should be used to denote people displaced by climate change and other environmental disruptions. As Lonergan (1998) said, it is extremely difficult to isolate the specific contributions of environmental factors from others such as social, economic, political, or institutional factors. Even if it is impossible to identify specific environmental effects on displacement, contemporary world cannot ignore the fact that worldwide environmental threats, such as climate change, deforestation, and sea -level rise may play a contributing role in affecting mass population movements.

Myers (1997) preliminarily estimated that approximately 162 million people worldwide are at risk from sea -level rise. Stern (2007) suggested that adverse climate change-related events could generate 200 million migrants by 2050, whereas Christian Aid (2007) predicted that up to one billion people could be displaced due to environment al causes by 2050. According to the United Nations High Commissioner for Refugees (UNHCR) (2012), environmentally induced migration and displacement could take on unprecedented dimensions, with predictions about the potential scale of such movements ranging from 25 million to one billion by 2050 . We have no idea whether or not the above estimations will be realized, but there is no doubt that the best solution is preventing the conditions that create EDPs while maintaining our current ecosystems. Even though it might be theoretically possible to mitigate all risks of creating EDPs, as limited aspects of those measures have clarified, attention toward how to adapt to those situations that generate EDPs has been 
growing. Thus, it is meaningful to consider several options in preparation for the anticipated risk of emerging EDPs.

\subsection{Mass Influx of Migrants}

Since 2011, 4.8 million Syrian refugees have fled to other countries, and the United Nations predicts that 8.7 million people are displaced within Syria (UNHCR, 2016). Many humanitarian agencies have stated that this is "the worst refugee crisis since World War II" (Amnesty International, 2015), and the worldwide media reports on this crisis almost every day. The Syrian refugee crisis is simply the largest worldwide humanitarian difficulty, and a typical case of sudden migrant influx. In the face of crises like this, everybody feels it is important to secure the safety and dignity of the refugees, but we have to pay attention to the effect of migration on host communities. As for the case of Syrian refugees, this crisis has brought tremendous challenges to the host communities in Lebanon, Jordan, Turkey, Iraq, and Europe.

Jacobsen (1996) defined a mass influx of refugees as large numbers (thousands) of people fleeing their places of residence for an asylum country within a relatively short period (a few years). Needless to say, it depends on indi vidual cases whether one refugee influx has the massive effects; moreover, it depends on the situation of the recipient states whether that causes a dispute. Generally, however, when massive numbers of migrants flow into one country all at once, the host community potentially faces various difficulties, such as strains on economic resources and physical infrastructure, security risks, and threats to government authority (Jacobsen, 1996). These burdens on the host communities may develop into conflicts between migrants and residents in the host community.

\subsection{Conflicts between Migrants and Host Communities}

Human migration sometimes generates tensions or conflicts between migrants and residents in the host community. There are many reasons for these conflicts.

Responses of residents in the host communities are split on how to handle migrants. Some people are generous and consider it important to support them a lot as much as possible. Others, however, are against absorbing migrants.

Fortunately, EDPs resulting from slow-onset movements such as sea -level rise and environmental degradations have a longer time to plan for resettlement compared with persons displaced by other causes (Nakayama, Yoshioka, Fujibayashi, \& Bruch, 2016). This means that international community has plenty of time to take effective measures to mitigate obstacles that will prevent EDPs from relocating in peace. In this study, we attempt to seek practical measures to address the resettlement of migrants resulting from environmental threats.

\section{Method}

This study attempts to explore useful and practical measures to mitigate the anticipated effect on host communities caused by the mass influx of migrants resulting from environmental threats. In addition to literature surveys, we conducted interviews from 2013 to 2016 with about 50 Fukushima evacuees from the town of Hirono who presently live in temporary housing in the city of Iwaki. We also interviewed Hirono government officials.

We also conducted field research in New South Wales (NSW) and South Australia (SA) to explore the Vietnamese and Bhutanese communities that live there. As well as observation, we interviewed more than 30 Vietnamese refugees in Cabramatta, (NSW) and about 10 Bhutanese refugees in Salisbury (SA). In several parts of our interviews, we applied the focus group interviewing method.

Lastly, we interviewed officers of relevant organizations dealing with migrants, including the UNHCR, the International Organization for Migration (IOM), and the International Federation of Red Cross and Red Crescent Societies (IFRC), to find out how they have tried to help voluntary and involuntary migrants respectively.

\section{Results}

\subsection{Past Lessons of Conflicts between Migrants and Host Communities}

Once massive numbers of migrants suddenly flow into one country, worries arise about the emergence of severe conflicts or tensions between migrants and residents in the host community. In this section, we attempt to learn from past lessons regarding conflict between migrants and host communities resulting from massive migrant influx.

\section{Local Economy}

Massive migrant influx has an economic effect on the local economy of the recipient communities. The economic effect is not necessarily negative - there may be some positive aspects to the effect of a refugee influx on the economy of the recipient countries. For example, the presence of migrants may attract development agencies to the host areas, and it could generate some economic stimulus leading to the development of host communities (UNHCR Standing Committee, 1997). However, there is no doubt that a large- scale influx of migrants is likely to constitute a heavy burden for receiving countries, and this could grow into tensions or conflicts between migrants and host communities. 
Achilli (2015) stated that, in Jordan, the protracted nature of the Syrian refugee crisis has negatively affected the living conditions. Jordanians, who welcomed refugees at first, later became hostile, and the belief that refugees we re thriving on scarce local resources was widespread amongst increasingly resentful host communities. This is because migrants, as soon as they are resettled, compete with the local citizens for scarce resources such as land, water, housing, food, and medical services. With time, their substantial demands lead to natural resources, education and health facilities, energy, transportation, social services, and employment (UNHCR Standing Committee, 1997). For example, Turkey, which has suffered from population inflow from Syria since 2011, has experienced the inflation of food and housing prices. The steep price increases in these categories have disproportionately affected the lower income natives (Akgündüz, van den Berg, \& Hassink, 2015).

As well as resource competition or inflationary pressures on prices, migrant influx may have impacts an effect on the local labor markets, causing wage depression. Akgündüz, van den Berg, \& Hassink (2015) found that there was no effect from the refugee inflow on the employment rates in the regions hosting refugees in Turkey, but the job market constituted a clear point of friction between migrants and local residents in Jordan. The Jordanian government has generously granted residency status for Syrian refugees in their country, but the go vernment has not granted them work permits. Jordan has one legislative system to permit expatriates with legal residency and valid passports to obtain work permits, but it is quite difficult for Syrian refugees just $1 \%$ of refugee households have a member with a work permit (UNHCR, 2014). The result is that many refugees work informally. As such, Jordanians often perceive Syrians as competitors for jobs, and this has led to protests and tensions between refugees and host communities (Achilli, 20 15).

\section{Security}

Concerns about insecurity resulting from the mass influx of migrants may grow into hostility toward migrants. Refugee inflow to Kenya in the early 1990s is a one case of a massive migrant influx. Since 1991, as many as 100,000 Somali refugees have arrived in Kenya; additionally, hundreds of thousands of refugees came from Somalia and Sudan in the following several years (Banki, 2004). Through the examination of various acts of violence in and around refugee camps, Crisp (1999) suggested that the level of violence in refugee populated areas in Kenya is unacceptably high, and the problem is actually getting worse. In addition, local residents have often complained that refugees add to security problems in general, including crime rates, theft, murder, prostitution, and alcoholism (UNHCR Standing Committee, 1997).

As well as complaints from residents in the host community, the influx of large numbers of refugees attracts severe hostility from the recipient state governments. In this case, the Kenyan government has accused refugees, especially those from Somalia, of smuggling firearms and escalating crime and insecurity (Kagwanja, 2002). Currently, the Kenyan government plans to close the Dadaab refugee camp, the world's largest refugee camp (CNN, 2016). Kenya says Dadaab has become a hive for the al-Shabab armed group (Al Jazeera, 2016). Whether thisit is the case or not, it is clear that security issues have a grave negative effect on host communities.

\section{Social Effects}

The massive inflow of migrants may hamper the school system of the host community. Houston, Texas absorbed a number of evacuees from the state of Louisiana after Hurricane Katrina massively damaged the state in August of 2005. Shortly after, more than 5,000 students from Louisiana started attending school in Houston in September of 2005. As a result, severe feuds took place between two groups of high school students, namely those from New Orleans and those originally in the host community. The Wall Street Journal (2005) reported that "Tensions also have boiled over in other Texas cities that have enrolled Katrina refugees, including San Antonio and Dallas."

The differences of cultures between the two student groups - in terms of clothes, hair style, slang language use, and behavior toward others - were found to be major causes of the conflicts. The conflicts were eased when "Several troublesome New Orleans students dropped out, and administrators reassigned some belligerent Houston students to another school." (Wall Street Journal, 2005). This case clearly shows the danger of believing in the "melting pot" hypothesis between migrants and those in the host community. Carrying capacity of schools in the host community should somehow be estimated before determining the number of students to be absorbed from outside.

\section{Assistance Differentiation}

On March 11, 2011, the Great East Japan Earthquake and the subsequent explosion at the Fukushima Daiichi Nuclear Power Plant displaced more than 470,000 people from their homes. More than 140,000 people were still away from their homes as of August 2016 (Reconstruction Agency, 2016). From 2013 to 2016, we conducted interviews in several of the affected areas of this large disaster. For example, we carried out interviews with about 50 evacuees from Hirono in the Fukushima Prefecture who were then living in temporary housing in Iwaki (also in the Fukushima Prefecture, next to Hirono). Through our interviews in various temporary housings, we witnessed and learned about the presence of 
severe hostility between the residents of Iwaki and the evacuees from the contaminated areas of the Fukushima Prefecture. Kawazoe (2014) and Reuters (2014) also reported the presence of conflicts between the evacuees and those in the host community. Although both the contaminated and un-contaminated municipalities were located in the Fukushima Prefecture, the way the residents of each were compensated (or not) differed greatly, because compensation was given to those who lived in the contaminated areas, which located within 30 kilometers of the Fukushima Daiichi nuclear reactor. The evacuees from Hirono were compensated, whereas the citizens of Iwaki (which is next to Hirono) were not. That is why some (if not all) citizens of Iwaki became hostile toward the evacuees from Hirono and other contaminated municipalities. This hostility grew into conflict.

\subsection{Successful Integrations into the Host Community}

Why did the above conflicts occur? How can we avoid those conflicts? We aim to explore meaningful implications from the lessons of the resettlement of Bhutanese refugees, which is the largest and most successful third- country resettlement program.

Bhutanese refugees are originally the descendants of Nepalese migrants resettling in southern Bhutan in the late 1890s (IOM, 2008). Although the Bhutanese government granted citizenship to these ethnic Nepalese under the 1958 Citizenship Act, the 1988 census, which took place only in southern Bhutan, classified many ethnic Nepalese as "illegal immigrants" (Commonwealth of Australia, 2007). Under the "One People, One Nation" policy, which King Jigme Singye Wangchuck adopted in 1989, many ethnic Nepalese faced difficulties and insecurity, and thus escaped from Bhutan to Nepal and India in the early 1990s. The Bhutanese and Nepalese governments held a total of 15 bilateral talks with no agreed outcome, thus prolonging instability in the refugee camps (Nepali Times, 2014).

The core group countries determined to give hopeful opportunities for Bhutanese refugees to resettle in the third countries in 2007, and these countries have accepted more than 100,000 Bhutanese refugees in the following way: the United States -84,819; Canada -6,500; Australia-5,554; New Zealand-1,002; Denmark-874; Norway-566; the Netherlands - 327; the United Kingdom-358 (UNHCR, 2015). Hence, the refugee population living in seven camps in eastern Nepal has decreased from 108,000 to less than 18,000, and just two camps now remain.

In order to explore the circumstances of Bhutanese refugees in the resettlement area, we went on a research trip to South Australia. Besides observation, we interviewed about 10 Bhutanese refugees in Salisbury (SA). Although it is quite difficult to create situations that are desirable for all members of migrants and residents in host communities, the case of Bhutanese refugees in South Australia was doubtlessly successful and contains many meaningful lessons. Through our research in South Australia, we witnessed a good atmosphere among Bhutanese refugees as well as between the refugees and the host community.

Why did the Bhutanese refugees successfully integrate into host communities in South Australia? Why did conflicts not occur? A variety of factors (such as social, economic, political, or institutional) influence migrant resettlements, and so it is difficult to identify the specific contributions of one factor from those of others. For instance, Salisbury is an industrial region near Adelaide, the capital city of South Australia, and so there are many employment opportunities in factories or farms. Thanks to the refugee schools, adult education, vocational training in refugee camps, and generous supports from governments and assistance agencies in South Australia, Bhutanese refugees have smoothly reconstructed their livelihoods. In addition, South Australia has accepted many refugees from Vietnam, Afghanistan, Myanmar, and so on. Those experiences have had a positive effect on the smooth resettlement of Bhutanese refugees. As mentioned the above, there are several factors behind the success of the Bhutanese refugees' resettlement in South Australia, but it would have been impossible unless the resettlement process had proceeded gradually and with plenty of time.

\subsection{Avoiding Conflicts}

Today, facing a massive migrant influx, European states aim at slowing the influx of migrants (Wall Street Journal, 2015). Once massive numbers of migrants flow into one country at once, there is likely to be severe conflicts between migrants and residents in the host community. It is the same in the case of EDPs. Why do these conflicts occur? How should we behave to avoid these conflicts? What options are feasible to avoid the severe conflicts between migrants and host communities? We answer these questions by proposing a way to avoid the one-time mass influx of migrants-let the refugees resettle gradually as economic migrants and through several decades. Figure 1 illustrates this concept. 


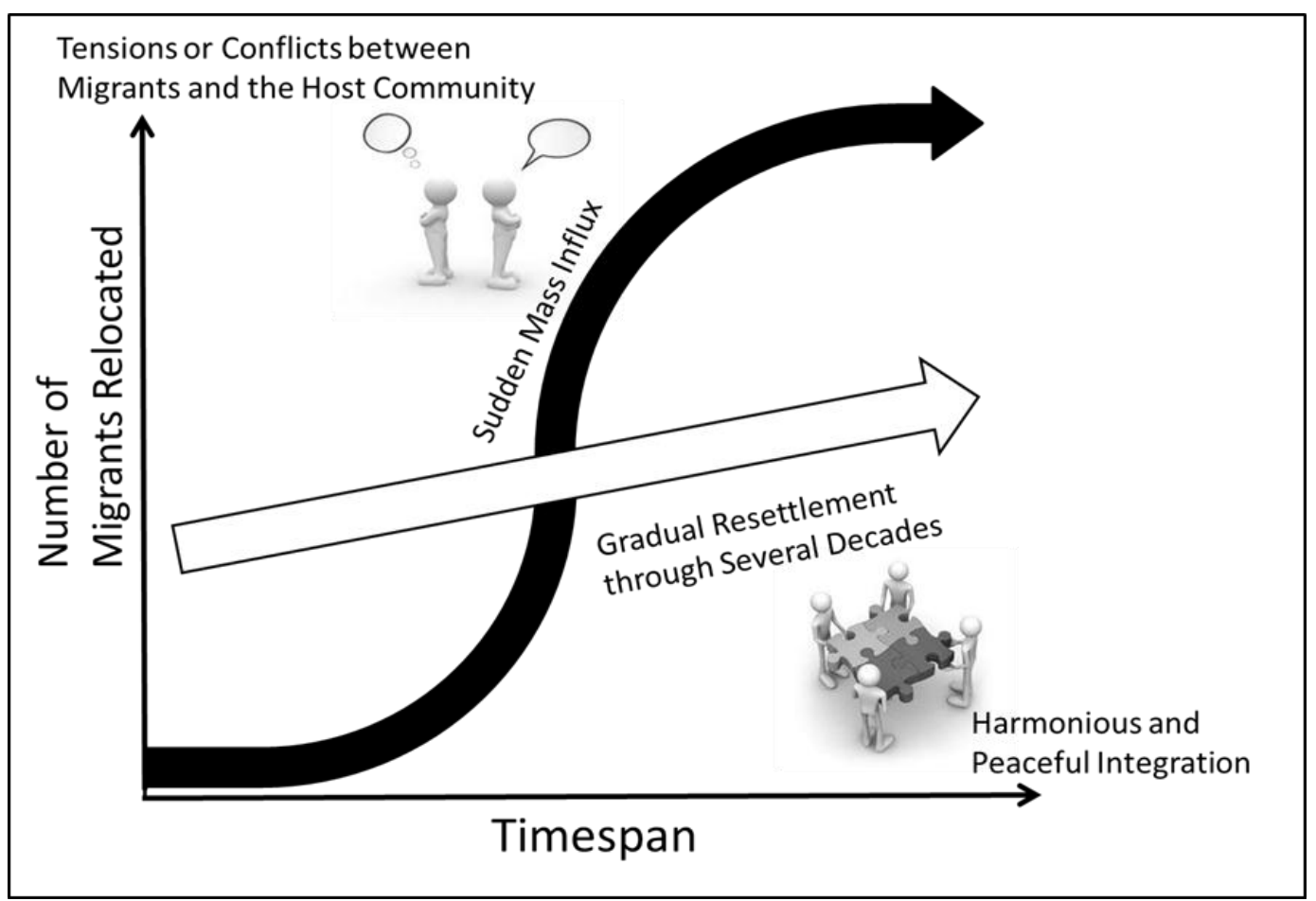

Figure 1. An option to avoid the mass influx of migrants resulting from environmental threats

As we mentioned above, EDPs resulting from the slow-onset effects of environmental threats have a longer time to plan for resettlement compared to displaced persons by other causes (Nakayama, Yoshioka, Fujibayashi, \& Bruch, 2016). Therefore, we propose that such individuals relocate slowly as economic migrants. This option seems preferable both for EDPs and for the host community, rather than tackling a mass influx of EDPs all at once after the effect of environmental threats become tangible and unavoidable. By allowing plenty of time for resettlement, internatioanal community can avoid a future mass influx of EDPs and the conflicts that follow with the host communities. As well, and as a matter of course, migrants would be permitted to work in resettlement areas because they are economic migrants. This option does not necessarily hinder international donors supporting them, but rather helps them to maintain their dignity as well as their livelihoods.

In this sense, "voluntary migration schemes" that enables people in highly vulnerable countries towards environmental threats to legally resettle and work in other countries can be a useful measure to mitigate the risks of future massive displacement. As Farquhar (2014) already argued the importance of the voluntary migration schemes to ensure Pacific peoples are able to migrate with dignity, for example, the Compact of Free Association (COFA) between the US and Martal Islands or the Pacific Access Category (PAC) visa between New Zealand and Kiribati, Tuvalu or Fiji may already be valued as a practical measurement backing up our proposing arguments. Although the existing "voluntary migration schemes" are never primarily planned for addressing the displacement risks, such schemes seem potentially become a risk-hedge tool towards environmental threats and displacement. In practice, these schemes can be more feasible by building upon the current immigration framework, and including the extension of current permanent and/or temporary migration schemes, as well as the introduction of labor-training migration schemes (Farquhar, 2014).

Needless to say, the obvious and desired solution is to prevent the conditions that create EDPs by maintaining current ecosystems. However, it is quite difficult to remove all risks that generate EDPswhile today's world is required to strenghnes its efforts to address the growing environmental threats. The international community is responsible for responding to any risk resulting from environmental threats, and we should consider several options in preparation for the anticipated risk of emerging EDPs. Our proposal needs to be considered as one practical measure for preventing a future mass influx of migrants resulting from environmental threats.

\section{Discussion}

\subsection{Necessary Timespan for Integration}

We carried our field research in Cabramatta (NSW) to investigate the Vietnamese community. In addition to observing, we interviewed more than 30 Vietnamese refugees, including community workers. Cabramatta is a tiny suburb near Sydney, and it has the biggest Vietnamese community in Australia (SBS, 2012). 
After the fall of Saigon (the fall of the South Vietnam Government) in 1975, many people escaped from Vietnam (mainly from South Vietnam). In the following decade, as many as two million people fled Vietnam, initially seeking refuge in neighboring refugee camps in Southeast Asia and later resettling in the United States, Canada, Australia, France, and others. About 700 Vietnamese people lived in Australia prior to 1975, but by 1982, 57,770 Vietnamese refugees had resettled there (SBS, 2015). Many more had resettled through Australian refugee intake and followed the family reunion program until the mid-1990s. According to the 2011 census, 185,039 Vietnamese-born people live in Australia (Department and Immigration and Citizenship, 2012).

It has been almost 40 years since Vietnamese refugees began to resettle in Australia. Today, Vietnamese refugees and their second generations lead fulfilling lives. The Vietnamese community has been growing, and it has overcome many obstacles including tensions or hostilities with other ethnic groups. Recently, more and more Vietnamese people, particularly among the second generation, have trained for highly skilled jobs such as doctors, lawyers, and public accountants and they have greatly contributed to both the Vietnamese community and Australian society in general. However, we have to take careful note that it took much time to come to today's situation. There were many struggles between the various actors, including governments, assistance agencies, and, of course, the Vietnamese migrants themselves.

As can be seen from this case of the Vietnamese in Australia, it generally takes plenty of time for migrant people to integrate into the host community. For migrants resulting from environmental threats, how long is necessary for successful integration into a host community? Needless to say, it depends on the individual case; howe ver, those struggles may not come to an end until the second or third generations become leading actors in the migrant communities. Yet the case of Vietnamese in Australia also implies that time highly influences their resettlement outcomes in Australia. Nakayama and Matsumoto (2016) also suggest, in the case of Tokuyama Dam in Japan, "true merger took place not by the first generation but by the second generation, who went to the same schools and made friends from childhood (p. 327)". Desirable situations of refugee integration cannot be realized in a day. If taking much time is an indispensable part of migrant integration, our proposal might be an ans wer because its process would proceed through decades. To sum up, it is important for the international community to make its efforts in the long run to make the desirable situations for both refugees and their host communities.

\subsection{Feasibility of this Option}

Who is an EDP? Who is not an EDP? It is a pending matter on how to select the beneficiaries for our option. As Lonergan (1998) said, isolating specific environmental factors from other factors - social, economic, political, or institutional-is extremely difficult. As well, it is more difficult to clarify all risks generating EDPs beforehand. Some people who are not recognized as EDPs at first might become EDPs later. In order to enhance the feasibility of this option, however, we must set some criteria. By the end of 2015, 65.3 million people were forcibly displaced worldwide as a result of persecutions, conflict, generalized violence, or human rights violations (UNHCR, 2016). However, the capacity of the international community to protect them was quite insufficient. With these various situations in mind, it is unrealistic to resettle all people who are said to be at risk from environmental threats, even if we could resettle them slowly as economic migrants. Therefore, it seems inevitable to set some criteria to select the beneficiaries of our proposal.

On the other hand, we must realize that such criteria could cause the risk of generating hostilities and conflicts among migrants. That is to say, setting some criteria and differentiations might lead to further tensions or hostilities between those who are allowed to resettle and those who are not, especially when migrants from both groups come into contact in some way (Nakayama, Fujibayashi, \& Yoshioka, 2016). From a view point of equity and fairness, how to set criteria is a significant problem. Although it is inevitable, to some extent, to distinguish between those who are allowed to be resettled and those who are not, we have to treat people on both sides of this distinction equally as much as possible in order to avoid future conflicts. Striking a balance between these two incompatible tasks is very controversial, but greatly significant.

\subsection{Balance between Community Formation and Local Integration}

We should also balance community formation and local integration. The creation of a migrant community is inevitable to some extent, and this would assist migrants with smoothly restoring their livelihoods in the resettlement place. Preserving their own language, culture, customs, and life style may contribute to enhancing the possibility of their successful resettlement with dignity.

On the other hand, it might become an obstacle for integration into the host community if migrants have little opportunity to relate with local residents. For example, in Cabramatta, Vietnamese refugees have created one ethnic community tied with strong kinship and, thus, they have not had to interact with non-Vietnamese people within the larger community. This feature is seen more often among people who do not work outside of the migrant community, such as elderly people or housewives. Croshaw (2017) suggests that tensions were also abserved in the Maldi ves, in the case of 2004 Indian Ocean Tsunami, between evacuees from the impacted atolls and those in the host community. In 
addition, "the different island identities sometimes created social conflicts between and within IDP families and with their hosts. Some communities did not want to accept IDP housing, particularly if the IDPs were from a different island because of these strong island identities and safety concerns (Croshaw, 2017, p129)". We do not deny the importance of migrants creating a community tied with their kinship, but we should pay attention to the negative aspects of this and struggle to harmonize the demands of migrants with those of the residents in host communities.

\section{Acknowledgements}

This work was supported by JSPS KAKENHI Grant Number JP16H03320, the Agency of Natural Resources and Energy of the Ministry of Economy, Trade, and Industry, and the Graduate School of Frontier Sciences of the University of Tokyo.

\section{References}

Achilli, L. (2015). Syrian refugees in Jordan: A reality check. Migration Policy Centre Robert Schuman Centre for Advanced Studies - European University Institute. Retrieved from http://cadmus.eui.eu/bitstream/handle/1814/34904/PolicyBriefMPC_2015_02.pdf?sequence=1

Akgündüz, Y. E., Van den B. M., \& Hassink, W. (2015). The impact of refugee crises on host labor markets: The case of the Syrian refugee crisis in Turkey. IZA Discussion Paper No. 8841.

Al Jazeera. (2016). Kenya's plan to shut Dadaab refugee camp criticized. Retrieved from http://www.aljazeera.com/news/2016/06/dadaab-refugee-camp-somalia-diplomat-opposes-closure-1606030516141 21.html

Amnesty International. (2015). The global refugee crisis. A conspiracy of neglect. Retrieved from http://www.amnestyusa.org/sites/default/files/p4575_global_refugee_crisis_syria.pdf

Amnesty International. (2015). World leaders' neglect of refugees condemns millions to death and despair. Retrieved from

https://www.amnesty.org/en/latest/news/2015/06/world-leaders-neglect-of-refugees-condemns-millions-to-death-a nd-despair/

Banki, S. (2004). Refugee integration in the intermediate term: A study of Nepal, Pakistan, and Kenya. UNHCR Working Paper No. 108.

Christian Aid. (2007). Human tide: The real migration crisis. Retrieved from https://www.christianaid.org.uk/Images/human-tide.pdf

CNN. (2016). Kenya to close refugee camps, displacing more than 600,000., Retrieved from http://edition.cnn.com/2016/05/06/africa/kenya-closing-refugee-camps/

Department of Immigration and Citizenship. (2007). Bhutanese Community Profile. Commonwealth of Australia.

Department of Immigration and Citizenship. (2012). Community Information Summary Vietnam-born. Commonwealth of Australia.

Crisp, J. (1999). A state of insecurity: The political economy of violence in refugee-populated areas of Kenya. UNHCR Working Paper No. 16.

Croshaw, H. R. (2017). In the wake of the 2004 Great Indian Ocean Tsunami: Internally displaced persons and the natural disaster response in the Maldives. Journal of Asian Development, 3(1), 125-143. https://doi.org/10.5296/jad.v3i1.10755

El-Hinnawi, E. (1985). Environmental refugees. Nairobi, Kenya: United Nations Environment Programme.

Farquhar, H. (2014). "Migration with Dignity": Towards a New Zealand Response to Climate Change Displacement in the Pacific. Submitted for the LLB (Honours) Degree Faculty of Law, Victoria University of Wellington. Retrieved from http://researcharchive.vuw.ac.nz/xmlui/bitstream/handle/10063/4302/thesis.pdf?sequence=2

International Organization for Migration. (2008). Cultural profile: The Bhutanese refugees in Nepal; A tool for settlement workers and sponsors.

Jacobsenm, K. (1996). Factors influencing the policy responses of host governments to mass refugee influxes. The International Migration Review, 30(3), 655-678. https://doi.org/10.2307/2547631

Kagwanja, P. M. (2002). Strengthening local relief capacity in Kenya: Challenges and prospects., Juma, Monica Kathina, \& Suhrke, Astri (Eds.), Eroding Local Capacity - International Humanitarian Action in Africa.

Kawazoe, S. (2014). Policy-related division of victims and social conflicts after a nuclear disaster: Acase study on Iwaki City [in Japanese]. Waseda RILAS Journal, 2. 
Lonergan, S. (1998). The role of environmental degradation in population displacement. Environmental Change and Security Project report, 4(4), 5-15.

Myers, N. (1997). Environmental refugees. Population and Environment, 19(2), 167-182. https://doi.org/10.1023/A:1024623431924

Nakayama, M., Yoshioka, N., Fujibayashi, H., \& Bruch, C. (2016). Factors affecting livelihood re-establishment of climate change induced transboundary displaced persons. International Journal of Social Science Studies, 4(9), 40-48. https://doi.org/10.11114/ijsss.v4i9.1744

Nakayama, M., Fujibayashi, H., \& Yoshioka, N. (2016). Applying past lessons learned to the relocation of climate change induced transboundary displaced persons. International Journal of Social Science Research, 4(2), 66-77. https://doi.org/10.5296/ijssr.v4i2.9718

Nakayama, M., \& Matsumoto, K. (2016). From Deep in the Mountains: The Miboro and Tokuyama Dams in Japan, Asian Journal of Environment and Disaster Management, 7(4), 321-332.

Nepali Times. (2014). An (inter)national disgrace; SAARC fails to confront the Bhutan refugee issue. Retrieved from http://nepalitimes.com/regular-columns/The-gadfly/saarc-fails-to-confront-bhutanese-refugees-issue, 401

Reconstruction Agency. 復興庁. (2016). Zenkoku no hinansya no kazu. 全国の避難者の数. Retrieved from http://www.reconstruction.go.jp/topics/main-cat2/sub-cat2-1/20160830_hinansha.pdf

Reuters. (2014). Fukushima fallout: Resentment grows in nearby Japanese city. Reuters, 31. Retrieved from http://www.reuters.com/article/uk-japan-nuclear-resentment-idUSKBNOGV0XN20140831 on 19 September 2016.

SBS. (2012). One day in Cabramatta. Artarmon NSW, Australia:SBS.

SBS. (2015). The Vietnamese refugees who changed white Australia. Retrieved from http://www.sbs.com.au/news/article/2015/04/14/vietnamese-refugees-who-changed-white-australia

Stern, N. H. (2007). The economics of climate change: The Stern review. Cambridge, England: Cambridge University Press. https://doi.org/10.1017/CBO9780511817434

United Nations High Commissioner for Refugees. (2012). The state of the world's refugees: In search of solidarity. Retrieved from http://www.unhcr.org/4fc5ceca9.pdf

United Nations High Commissioner for Refugees. (2014). Living in the sShadow_Jordan home visits report 2014. Retrieved from http://www.unhcr.org/54b685079.pdf

United Nations High Commissioner for Refugees. (2015). Resettlement of Bhutanese refugees surpasses 100,000 mark. Retrieved from http://www.unhcr.org/news/latest/2015/11/564dded46/resettlement-bhutanese-refugees-surpasses-100000-mark.ht $\mathrm{ml}$ ?query=Bhutanese $\% 20$ refugee

United Nations High Commissioner for Refugees. (2016). Global trends: Forced displacement in 2015. Retrieved from http://www.unhcr.org/statistics/unhcrstats/576408cd7/unher-global-trends-2015.html?query=global\%20trends

United Nations High Commissioner for Refugees. (2016). Syria emergency. Retrieved from http://www.unhcr.org/syria-emergency.html

UNHCR Standing Committee. (1997). Executive committee of the High Commissioner's programme. (6th Meeting, January 6, 1997): Social and economic impact of large refugee populations on host developing countries; EC/47/SC/CRP.7. Retrieved from

http://www.unhcr.org/uk/excom/standcom/3ae68d0e10/social-economic-impact-large-refugee-populations-host-de veloping-countries.html

Wall Street Journal. (2005). Teen tension trails hurricane evacuees into Houston school., Wall Street Journal, 2. December 2005, Rretrieved from http://www.wsj.com/articles/SB113349151947412113 on 19 September 2016.

Wall Street Journal. (2015). European leaders aim to slow influx of migrants. Retrieved from http://www.wsj.com/articles/eu-plan-to-stem-flow-threatens-to-throw-migrants-into-limbo-1445764778

\section{Copyrights}

Copyright for this article is retained by the author(s), with first publication rights granted to the journal.

This is an open-access article distributed under the terms and conditions of the Creative Commons Attribution license which permits unrestricted use, distribution, and reproduction in any medium, provided the original work is properly cited. 